\title{
Novel Strategies for Nanoparticle-Based Radiosensitization in Glioblastoma
}

\author{
Henry Ruiz-Garcia ${ }^{1,2}$, Cristopher Ramirez-Loera ${ }^{2}{ }^{(\mathbb{D}}$, Timothy D. Malouff ${ }^{1}$, Danushka S. Seneviratne ${ }^{1}$, \\ Joshua D. Palmer ${ }^{3}$ (D) and Daniel M. Trifiletti ${ }^{1,2, *}$
}

1 Department of Radiation Oncology, Mayo Clinic, Jacksonville, FL 32224, USA; ruizgarcia.henry@mayo.edu (H.R.-G.); Malouff.timothy@mayo.edu (T.D.M.); Seneviratne.Danushka@mayo.edu (D.S.S.)

2 Department of Neurological Surgery, Mayo Clinic, Jacksonville, FL 32224, USA; cvrl_69@live.com.mx

3 Department of Radiation Oncology, Ohio State University, Columbus, OH 43210, USA; Joshua.palmer@osumc.edu

* Correspondence: Trifiletti.Daniel@mayo.edu

Citation: Ruiz-Garcia, H.;

Ramirez-Loera, C.; Malouff, T.D.;

Seneviratne, D.S.; Palmer, J.D.;

Trifiletti, D.M. Novel Strategies for Nanoparticle-Based

Radiosensitization in Glioblastoma. Int. J. Mol. Sci. 2021, 22, 9673 . https://doi.org/10.3390/ijms22189673

Academic Editor: Ivan Kempson

Received: 15 August 2021

Accepted: 3 September 2021

Published: 7 September 2021

Publisher's Note: MDPI stays neutral with regard to jurisdictional claims in published maps and institutional affiliations.

Copyright: (c) 2021 by the authors. Licensee MDPI, Basel, Switzerland This article is an open access article distributed under the terms and conditions of the Creative Commons Attribution (CC BY) license (https:// creativecommons.org/licenses/by/ $4.0 /)$

\begin{abstract}
Radiotherapy (RT) is one of the cornerstones in the current treatment paradigm for glioblastoma (GBM). However, little has changed in the management of GBM since the establishment of the current protocol in 2005, and the prognosis remains grim. Radioresistance is one of the hallmarks for treatment failure, and different therapeutic strategies are aimed at overcoming it. Among these strategies, nanomedicine has advantages over conventional tumor therapeutics, including improvements in drug delivery and enhanced antitumor properties. Radiosensitizing strategies using nanoparticles (NP) are actively under study and hold promise to improve the treatment response. We aim to describe the basis of nanomedicine for GBM treatment, current evidence in radiosensitization efforts using nanoparticles, and novel strategies, such as preoperative radiation, that could be synergized with nanoradiosensitizers.
\end{abstract}

Keywords: nanoparticle; radiotherapy; radiosensitization; glioblastoma; stem-cells; theranostic

\section{Introduction}

Glioblastoma (GBM) is the most common and devastating primary brain cancer, with an age-adjusted incidence rate of 3.23 per 100,000 population and 12,000 annual average cases, accounting for $57.7 \%$ of gliomas and $48.6 \%$ of all malignant brain tumors [1]. However, despite extraordinary efforts to improve outcomes, very few therapies have impacted the current standard of care, reflected in median overall survival (OS) of 14.6-16 months and a 5-year survival rate of $4.6 \%$ [2-7] with optimal treatment patterns.

The current standard therapy includes maximal safe resection and adjuvant chemoradiation $[2,5,6]$. The use of radiation in patients diagnosed with gliomas is a therapeutic cornerstone that has allowed for further improvement in median OS and quality of life. The first randomized clinical trial, which was performed more than 40 years ago by Walker et al., showed that radiation was able to improve the median OS compared to the control groups (carmustine (BCNU) alone) by 16 weeks, resulting in 34.5 weeks vs. 18.5 weeks [3]. Later, the same group showed similar results and an improvement in survival with use of radiation [8]. Interestingly, the authors also concluded that the use of a nitrosourea could help increase the benefit of radiation. The current treatment paradigm for GBM was established in 2005, when Stupp et al. published the landmark paper showing an improvement in OS with the addition of temozolomide to radiation in a concomitant and adjuvant fashion [2]. Radiation plus temozolomide increased the OS from 12.1 months to 14.6 months when compared to radiation alone in patients with prior surgical resection. Furthermore, the 2-year survival rate also improved with the addition of temozolomide, from $10.4 \%$ to $26.5 \%$ [2]. Thus, the role for radiotherapy (RT) with temozolomide was established; however, no other agent has 
been able to further enhance its survival benefit despite a multitude of basic science and clinical studies.

The current therapeutic delivery systems in the treatment of GBM include hormone therapy, immunotherapy, gene therapy, radiation therapy, and the submicron systems (nanoparticles and liposomes) [9]. Any agent administered with therapeutic activity is exposed to biological barriers before reaching its target. In fact, certain properties in the microenvironment act as drawbacks in their interaction: bioavailability, solubility, degradation systems, and unexpected effects such as adjacent healthy tissue involvement. Therefore, the specific delivery of drugs to an organ, tissue, or a type of cell is mandatory. Submicron systems (nanoparticles (NP) and liposomes) serve as a vehicle capable of overcoming existing issues on the proper functioning of the therapeutic agent. Since there are many factors that limit therapeutic options for GBM patients, the use of nanomedicine and targeted approaches can improve the delivery, efficacy, and specificity of current and upcoming theranostics [10].

The main challenges in the treatment of GBM lie in the therapeutic specificity without affecting normal cells/healthy tissue and an environment prone to enhance the therapeutic effect. Additionally, the factors that agents must meet to reach the therapeutic target are as follows: (1) stable maintenance in the blood while reaching the tumor microenvironment; (2) escape from elimination systems such as the reticuloendothelial system and the phagocytic mononuclear system; (3) adequate accumulation in the tumor microenvironment through irregular tumor vasculature; (4) penetrance to the tumor interstitial fluid of the tumor microenvironment with high pressure; (5) reaching the active site and interacting with the target cells exclusively [10].

In this setting, NP have now arisen as potential radiosensitizers that can amplify the radiation-induced damage in GBM cells, directly, by physical mechanisms, or indirectly, by tackling radioresistance pathways. In the following sections we will discuss the basis of NP as well as previous and novel strategies to enhance the synergy between radiation and nanotechnology.

\section{Nanoparticles}

NP refer to nanomaterials with at least one of their external dimensions sized between 1 and $100 \mathrm{~nm}$ [11]. This small dimension is associated with a high surface/volume ratio, which confers physical and biological properties different from those of conventional materials. NP can be made from a variety of materials such as lipids, compositing polymers, proteins, metals, or semiconductors. Current nanoparticle platforms for tumors can be classified into three major categories including organic-based NP (e.g., liposomes, dendrimers, polymeric NP, micelles, and solid lipid nanoparticles), inorganic-based NP (e.g., iron oxide NP, gold NP, ceramic NP, semiconductor nanocrystals and carbon nanotubes) and hybrid NP (synthesized from two or more types of nanomaterials). An alternative design of nanoparticles may also contain intrinsic thermal, electrical, optical, or magnetic properties that can be served in imaging or therapeutic purposes [10]. Furthermore, these attributes can be tuned by modifying the size, shape, or surface of NP [12,13].

The possibility of tailoring NP properties according to specific interests makes them an appealing option in nano-oncology, as this opens the door to have them reaching out to specific tissues, cell types or even intracellular compartments for diagnostic or therapeutic purposes [14].

\subsection{Nanoparticle Targeting}

The process through which a NP interacts with a specific tissue, cell type, or cell compartment in a very selective manner is known as targeting. This can be classified as passive targeting (Figure 1A) or active targeting (Figure 1B), depending on whether this targeting ability is natural or engineered. 

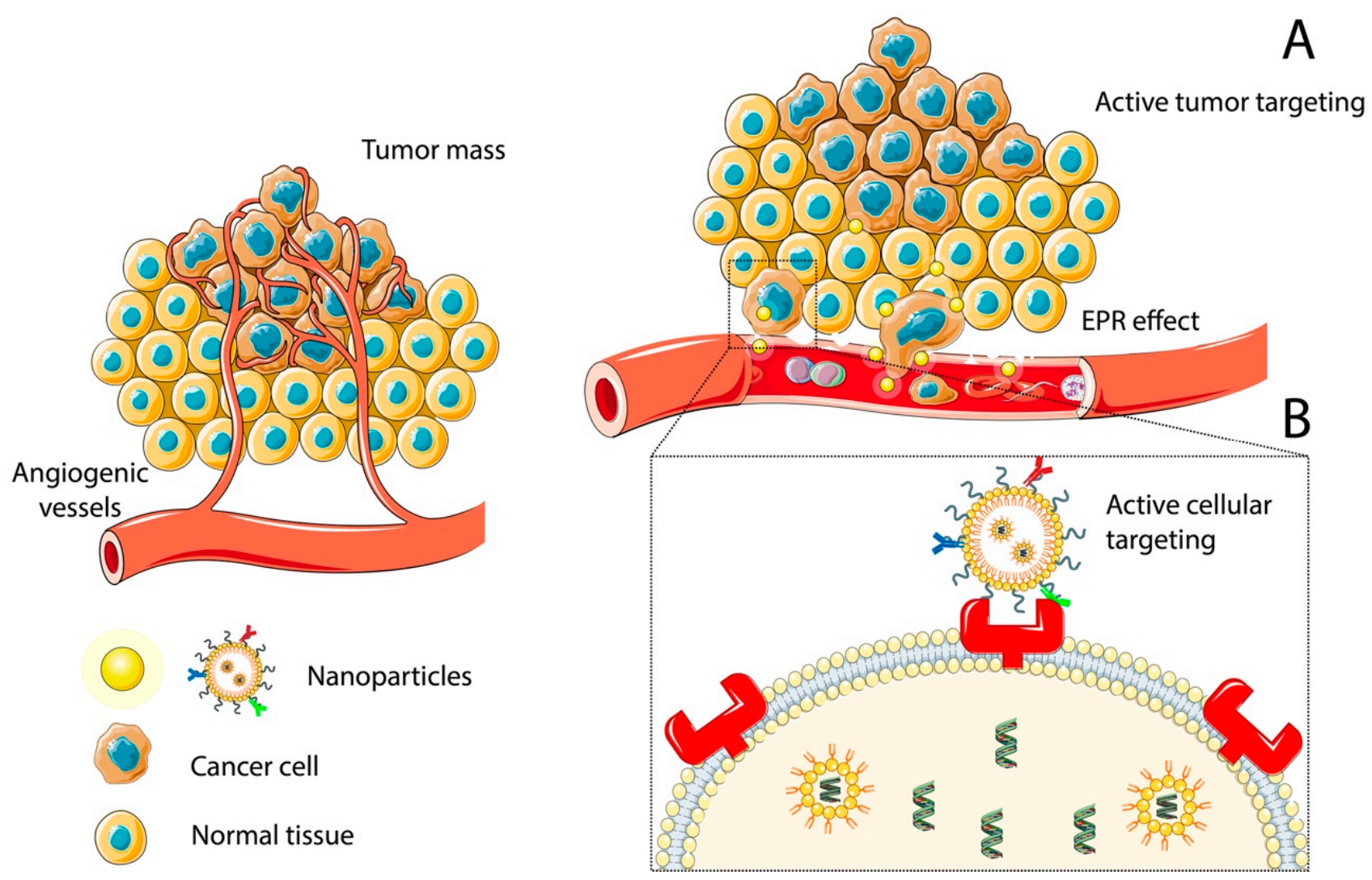

Figure 1. Different types of Nanoparticle Targeting utilized in Glioblastoma Treatment and Diagnosis. (A) As passive targeting takes advantage of factors such as nanoparticle size, BBB abnormalities, and EPR effect to reach the tumor tissue by diffusion, active tumor targeting utilizes specific properties of ligands and receptors to increase the interaction between the tumor cell and nanoparticle. (B) Active cellular targeting provides nanoparticles the capacity to be selectively engulfed by tumoral cells and localized in specific intracellular spaces, targeting organelles such as the nucleus. Abbreviations: BBB-blood-brain barrier, EPR—enhanced permeability and retention effect.

Active/passive targeting is the ideal solution to promote NP accumulation in the desired area. As the nucleus is ultimately the final target for many therapeutics, the surface interplay of a drug molecule does not entail necessary its interaction with its subcellular target. The active targeting of tumors can be performed not only by achieving tumor cells but also by localization of the nanocarriers in specific intracellular spaces or organelles, such as nucleus or mitochondria. In addition, active targeting implies reaching the tumor region, targeting the tumor microenvironment, targeting the vascularization of the tumor microenvironment, or directly targeting tumor cells with internalization, simultaneously considering the route of administration [10]. Evidently, active targeting involves the use of carriers bearing various surface ligands to achieve either transport across an intact bloodbrain barrier (BBB) or cell uptake following extravasation across a leaky BBB [15-17].

Both systems complement each other, increasing accumulation in the tumor region and actively binding to target receptors overexpressed in tumor cell surfaces. Since different delivery methods can benefit from passive/active targeting effects exploiting cellular phenomena in the tumor area, the biological and physicochemical properties of the drug and carrier must be considered.

2.1.1. Passive Targeting: The Role of the Enhanced Permeability and Retention Effect and PEGylation

Passive targeting refers to an inherent mechanism that allows NP to selectively accumulate in the tumor rather than in healthy parenchyma. 
In 1986, Matsumura et al. demonstrated that intravenous administration of Evans blue dye accumulated in tumor tissues but not in normal parenchyma, and this difference turned into $>5$-fold concentration of Evans blue within the tumor when compared to plasma concentrations after $12 \mathrm{~h}$ [18]. Importantly, this phenomenon was explained by the fact that Evans blue dye binds to plasma albumin once in the blood stream. A similar phenomenon was observed to happen with the use of radio-labeled plasma proteins such as transferrin $(90 \mathrm{kDa})$ and $\mathrm{IgG}(160 \mathrm{kDa})$. On the contrary, smaller proteins were noted not to accumulate within tumors $[19,20]$. Further studies demonstrated that macromolecules with a molecular weight above the renal thresholds $(40 \mathrm{kDa})$ might accumulate in cancerous tissues, as described before, caused by poor renal filtration and the existence of an abnormal and more permeable neoplastic vasculature. Maeda et al. also showed that when Evans blue dye was directly injected into the tumor, it was retained longer than when injected into healthy tissue, which was hypothesized to be related to an impaired functionality of the lymphatic drainage in the tumor [18].

The phenomenon described above is known as the enhanced permeability and retention (EPR) effect, and relies on the pathophysiological characteristics of tumor vessels, which are more permeable than healthy blood vessels [21,22]. This phenomenon also depends on the characteristics of the particle that is expected to reach the tumor. Thus, the EPR effect allows for the movement of NP with a sizable dimension into the tumor microenvironment, but not through healthy vessels, which are better sealed and prevent this movement $[19,20]$. This is possible given that NP with diameters of at least 5-10 nm have reduced kidney excretion different from conventional chemotherapeutics. They are usually $<1 \mathrm{kDa}$ and filter more easily through the kidney [23]. Consequently, these particles have enough time to move from the bloodstream into the tumor tissue.

Another important factor determining the accumulation of NP within the tumor is the circulation time, as a longer blood half-life will increase the likelihood of NP concentration within the tumor tissue. Additionally, coating NP with polymers such as poly(ethylene glycol) (PEG) (also known as PEGylation) represents an strategy to increase the circulation time, which is highly valuable for passive targeting [24].

PEGylation has an important effect on NP biodistribution, stabilization, and structure in vitro and in vivo [24-27]. PEG modification improves the circulation time by preventing NP engulfment by the mononuclear phagocyte system (MPS) and subsequent removal from circulation $[28,29]$. After PEG molecules bind the NP surface, they form a well hydrated inert hydrophilic layer that prevents the binding of other molecules via steric repulsion forces [30]. Thus, PEGylation increases NP stability in biological fluids with high-salt concentrations, such as the blood, where PEG help circumvent non-specific cell-protein interactions, such as those mediating opsonization, which could foster NP recognition and phagocytosis by MPS [28,30].

Overall, despite the role EPR effect and PEGylation on the distribution of NP within brain tumors, the BBB is still very restrictive. Given its cellular composition, tight junctions connecting endothelial cells and efflux pumps prevent molecules from penetrating the BBB [31]. Therefore, physicochemical properties, such as molecular weight, lipophilicity, and charge of targeted therapeutic molecules, are arduously studied [32].

Breakdown of the BBB is common in high-grade gliomas and brain metastases, defining the blood-brain tumor barrier (BBTB) [33]. The dysfunctional barrier grants a hyperpermeability property to the endothelium. Considering this state, drugs relying on EPR effect for delivery could be exploited for targeting macromolecules of the tumor.

Hence, other strategies are necessary to improve NP distribution more selectively. Active targeting is one of these strategies and will be discussed below.

\subsubsection{Active Targeting}

Active targeting refers to the process that allows NP to selectively distribute into specific cell types or even intracellular compartments (Figure 1B) [23]. This involves the design of specific moieties for NP biofunctionalization. Active targeting can be achieved by different methods. 
One of these methods is known as ligand targeting, this involves the selection and designing of specific ligands which will bind to the NP surface (biofunctionalization) to mediate the precise interaction between NP and the desired target cell [23]. This interaction between the ligand and the cell happen through cellular receptors/membrane proteins that may or may not lead to cellular internalization [34]. In general, these ligands can be classified as antibody or non-antibody ligands, each of these with pros and cons. Monoclonal antibodies (mAbs) or mAbs fragments have a high degree of specificity for the target tissue and a potentially regulable binding affinity [35-37]. An additional advantage derived from the use of mAbs is the possibility of synergy between the engulfed NP and the downstream antibody signaling [34,38]. The non-antibody ligands include molecules that bind to specific cell receptors, and in the case of GBM these ligands can be folic acid, hyaluronic acid, arginyl-glycyl-aspartic tripeptide (RGD) peptide, epidermal growth factor (EGF), and others [39]. However, although these non-antibody ligands enhance target specificity, they can still bind some non-target tissues as well as compete for the target receptor with free ligands, such as folate, that can also come from diet and reach high levels in plasma [34]. Any of the previously mentioned ligands can be directly or indirectly (i.e., after PEGylation) linked to the NP, and thus target cancer cells, tumor stromal cells, or tumor blood vessels [23].

\subsection{Nanoparticle Radiosensitization Efforts}

RT remains the primary treatment modality for unresectable GBM [40,41]. However, there are several drawbacks associated with this approach, including radioresistance due to tumor hypoxia, limitations in radiation dose due to normal tissue constraints, especially in the setting of previous radiation in recurrent tumors, and the lack of target specificity [42-44]. Therefore, it is clear that new approaches to improve the efficacy of radiation treatment for patients diagnosed with glioma are necessary.

Different approaches have been proposed to overcome these roadblocks, broadly falling into two main categories: (1) implementation of advanced RT techniques and, (2) development of a new generation of treatment agents that sensitize cells to ionizing radiation (radiosensitizers) by improving their relative biological effectiveness (RBE) [45]. Thus, the use of radiosensitizers is a potential approach to improve RT efficacy.

In this setting, NP have been tested as radiosensitizing agents as well as carriers of other radiosensitizing agents, with studies demonstrating promising results after photon and particle radiation $[44,46,47]$. This strategy using nanomedicine aims to load NP with drugs that sensitize cancer cells to radiation, and thereby enhance the killing of residual disease and prevent treatment resistance [48]. NP as radiosensitizers has been extensively explored over the past decades; but recently high atomic number $N P$, such as gadolinium $(Z=79)$, hafnium $(Z=72)$, platinum $(Z=78)$, gold $(Z=79)$ or bismuth $(Z=82)$ have been investigated [49]. The rationale relies on the amplification of radiation effects when activated by photons of $\mathrm{keV}$ to $\mathrm{MeV}$ energies, electrons, neutrons, or fast ions (>50 $\left.\mathrm{MeV} \mathrm{amu}^{-1}\right)[50,51]$.

Several studies have been designed to introduce NP as potential enhancers of RT efficacy. Gold nanoparticles (AuNPs) are an important category among the radiosensitizers due to their high stability, biocompatibility, high atomic number, and the ability to be synthesized at diverse sizes and characterizations [52]. Extensive preclinical studies have demonstrated significant local enhancement of the absorbed dose using AuNPs compared to kilovoltage $(\mathrm{kV})$ X-rays alone. The impact of these structures is attributed to the photoelectric effect, resulting in a high mass energy coefficient relative to soft tissue [44,53]. Kazmi et al. evaluated the radiosensitization effect on U87 GBM cells in the presence of $42 \mathrm{~nm}$ AuNPs and irradiated with clinical $6 \mathrm{MV}$ photon beam. They showed a significant improvement in radiosensitivity using AuNPs. Similarly, there was a significant difference in the surviving fraction between the GBM alone group and the GBM plus AuNPs group. With this design, Kazmi et al. demonstrated that U87 cells irradiated at 2 Gy using a clinical platform enhanced radiosensitization by acting in synergy with AuNPs [44]. Moreover, Kunoh et al. initially examined the cytotoxicity of DNA-generated AuNPs in human U251MG-P1 cells that had cancer stem cells' properties. Then, they studied the radiation 
sensitivity of the cells associated or unassociated with AuNPs. This group demonstrated that pretreatment of the cells with AuNPs abrogated the radioresistance of cancer cells [54]. Additionally, it did not induce apoptosis in the cells but enhanced the number of abnormal nuclei, causing cell death by mitotic catastrophe. Comparably, Hua et al. developed a novel radiosensitizing agent-containing NP to enhance the radiation effect on gliomas. A metronidazole-based hydrophobic core was synthesized, mixed with angiopep- 2 and lecithin, to self-assemble by nanoprecipitation. Within this core, doxorubicin (DOX) was encapsulated, and its contents released under hypoxic conditions. The nitro groups of metronidazole are converted to hydrophilic amino groups, which destabilize the NP and promote the release of DOX. This effect was assessed in both in vivo and in vitro models. Hua et al. demonstrated that these particles could deliver hydrophobic chemotherapy, achieving the effect of concurrent chemotherapy and radiation and inducing the release of hydrophobic chemotherapeutics under hypoxic conditions. Additionally, the in vitro and in vivo results demonstrated significant inhibition of glioma growth and efficient targeting of gliomas [40].

Intending to limit toxicity to surrounding healthy tissue and enhance radiation damage, different modes of locoregional drug delivery, such as stereotactic radiosurgery (SRS), are being developed [55]. Séhédic et al. investigated the in vivo cellular targeting of rheniumloaded lipid nanocapsules (LNC) in a locoregional strategy. In this study, the impact of the mutual action of intracerebral internal vectorized RT and active CXCR4-immunotargeting was investigated using $12 \mathrm{G} 5$-conjugated $\mathrm{LNC}^{188} \mathrm{Re}$ in a xenogeneic and orthotopic glioma model of human U87MG cells expressing the CXCR4 receptor implanted in Scid mice. CXCR4 is blockaded by function-blocking antibody $12 \mathrm{G}$, which is notably reported to inhibit SDF-1-induced GBM cell proliferation [55,56]. This group demonstrated that a 12G5$\mathrm{LNC}^{188}$ Re single infusion delivered by convection-enhanced delivery (CED) resulted in significantly improved median survival that was accompanied by locoregional effects on tumor development, including hypovascularization. Their findings support the hypothesis that the use and optimization of intracerebral active targeting of nanocarriers loaded with radiopharmaceuticals may lead to considerable benefits in human trials.

Image-guided RT presents a unique area of overlap with nanomedicine, specifically when using MRI-guided therapy with gadolinium. Gadolinum, with its high atomic number, allows for improved delineation of the tumor [57]. The strategy to enhance the imaging contrast and improve theranostic applications of chelating species includes coupling these agents to the surface of NP or incorporating them into nanostructures [58,59]. Le Duc et al. developed a family of ultrasmall gadolinium-based NP for MRI visualization and radiosensitization called AGuIX (Activation Guided by Irradiation by X-rays), to compare their efficiency for magnetic resonance imaging and radiosensitization to those of the commercial gadolinium based molecular agent. Two main types of NP were proposed with similar physico-chemical properties, radiosensitizing properties, and in vivo biodistribution profiles: polysiloxane core coated with DTPA (Diethylene Triamine Pentaacetic Acid) and molecules incorporating DOTAREM, a commercial gadolinium-based molecular agent [57]. They established a protocol consisting of microbeam RT $20 \mathrm{~min}$ after the injection of a specific quantity of gadolinium. The results show an increase in survival time to 102.5 days with AGuIX particles; this radiosensitizing effect could be explained by the persistent tumor uptake of the particles, inducing a significant nanoscale dose deposition under irradiation (Figure 2) [57]. 


\author{
DOSE AGENT \\ "radiosensitizing effect" \\ Made of high atomic \\ number material \\ Induces absorption of X-rays
}

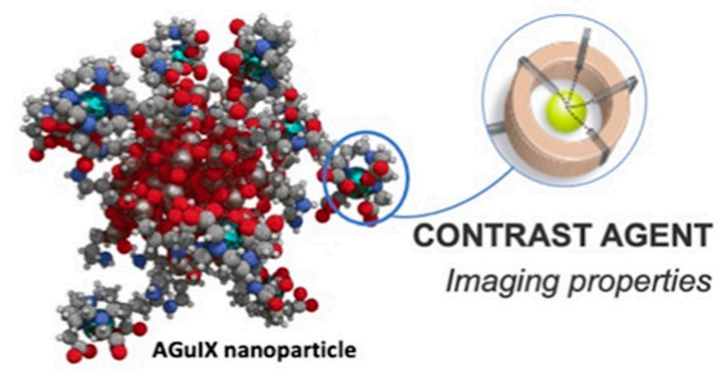

BIODISTRIBUTION

Nanoparticle size (<100 um)

in at least one dimension, decrease engulfment by

phagocytic/mononuclear system while

still crossing BBB

\author{
5nm-sized particle \\ Adequate renal elimination \\ (threshold at +- 40KDa)
}

\author{
Larger size than conventional \\ agents (usually $<1 \mathrm{KDa}$ ) \\ Allows adequate tumor targeting \\ due to EPR effect
}

Figure 2. Features of an Adequate Theragnostic Nanoparticle for Glioblastoma. Description of desirable features in a theragnostic nanoparticle, most of them are related to size and nature of nanoparticle. Imaging provided by Dr. Loeffler with permission (ref $[39,57,60])$.

Despite these promising initial results, the evidence for its clinical application is very limited. Currently, the gadolinium-based AGuIX was included in a phase I study protocol called NANO-RAD (NCT02820454) [61,62]. As AGuIX functions as a magnetic resonance imaging contrast and a radiosensitizer, the study aimed to investigate the safety and maximum tolerated dose of systemic administration in combination with whole-brain radiotherapy (WBRT) in patients with multiple brain metastases not suitable for stereotactic RT. Additionally, an MRI protocol was established to evaluate drug distribution in brain metastases and surrounding healthy tissues. Patients received WBRT of 30 Gy in 10 daily sessions over 2 weeks; AGuIX was administered intravenously $4 \mathrm{~h}$ before the first WBRT session. Patients with measurable brain metastases received escalating doses of AGuIX nanoparticles $(15,30,50,75$, or $100 \mathrm{mg} / \mathrm{kg}$ intravenously) on the day of initiation of WBRT (30 Gy in 10 fractions) in 5 cohorts of 3 patients each. The results show that of 15 patients with 354 metastases, no dose-limiting toxic effects were observed up to AGuIX $100 \mathrm{mg} / \mathrm{kg}$. Thirteen of 14 evaluable patients had stabilization or reduction of tumor volume. NP concentration after administration was proportional to the injected dose. MRI showed a correlation between contrast enhancement and tumor response. Thus, combining AGuIX with RT showed safety and tumor response, targeting brain metastases, and remaining within tumors for up to 1 week.

In this regard, CED of OS2966, an anti-CD29 (Beta1 integrin) monoclonal antibody, was included in a phase 1 study to determine if this drug, when delivered directly to the brain of adult patients with recurrent/progressive high-grade glioma (HGG), is safe and well tolerated [63]. This study is an open-label, dose-escalation, two-part study. Tumor tissue will be collected in both study parts to evaluate how well OS2966 targets malignant cells and to confirm the mechanism of action. All enrolled patients will also receive standard supportive care therapy. The lack of progress in treating malignant brain tumors is because of the complex environment where tumor growth occurs. Moreover, their radioresistance compared to the brain and the poor distribution of cytotoxic agents are important factors worth exploring by coupling NP as new radiosensitizers with additional fields to maximize its benefits. 
Current efforts, either in preclinical models or ongoing clinical trials in the treatment of GBM, are summarized in Table 1.

Table 1. List of current radiosensitizers used in clinical and preclinical models.

\begin{tabular}{|c|c|c|}
\hline Agent & Study Type & Treatment Regimen \\
\hline Gold nanoparticles (NP) & Preclinical & $\begin{array}{l}\text { Gold NP + clinical } 6 \mathrm{MV} \text { (megavoltage) photon } \\
\text { beam in U87 glioblastoma cells [44] }\end{array}$ \\
\hline Gold NP & Preclinical & $\begin{array}{l}\text { X-ray irradiation + Gold NP in U251MG } \\
\text { glioblastoma cells [54] }\end{array}$ \\
\hline $\begin{array}{l}\text { Folic acid decorated } \\
\text { gold nanoclusters }\end{array}$ & Preclinical & $\begin{array}{l}\text { Gold nanoclusters + } 6 \text { Gy radiation dose in C6 } \\
\text { rat glioma cells [52] }\end{array}$ \\
\hline Gold nanotriangles & Preclinical & $\begin{array}{c}\text { Gold nanotriangles }+250 \mathrm{kVp} \text { X-rays in U87MG } \\
\text { human glioblastoma cells [64] }\end{array}$ \\
\hline Silver NP & Preclinical & $\begin{array}{l}\text { Silver NP + } 6 \text { MV X-rays beams with linear } \\
\text { accelerator in U251 glioblastoma cells [65] }\end{array}$ \\
\hline Silver NP & Preclinical & $\begin{array}{c}\text { Silver NP + } 6 \text { MV X-rays beams with linear } \\
\text { accelerator in U251 glioblastoma cells and C6 } \\
\text { glioma cells [66] }\end{array}$ \\
\hline Graphene oxide NP as carrier of IUdR & Preclinical & $\begin{array}{l}\text { Graphene NP + } 8 \text { Gy radiation in C6 glioma } \\
\text { cells [67] }\end{array}$ \\
\hline Gadolinium-based AGuIX NP & Phase 1 clinical trial & $\begin{array}{l}\text { AGuIX NP injected IV + WBRT } \\
\text { (30 Gy/10 fractions) [68] }\end{array}$ \\
\hline RRx-001 & $\begin{array}{l}\text { Phase } 1 \text { clinical trial } \\
\text { (ongoing)-NCT02871843 }\end{array}$ & RRx-001 + TMZ (temozolomide) + radiation \\
\hline Sulfasalazine & $\begin{array}{l}\text { Phase } 1 \text { clinical trial } \\
\text { (ongoing)-NCT04205357 }\end{array}$ & Sulfasalazine + stereotactic radiotherapy \\
\hline NVX-108 & $\begin{array}{l}\text { Phase } 2 \text { clinical trial } \\
\text { (ongoing)-NCT03862430 }\end{array}$ & NVX-108 + TMZ + radiotherapy \\
\hline Carboplatin & $\begin{array}{l}\text { Phase } 1 \& 2 \text { clinical trial } \\
\text { (ongoing)-NCT03672721 }\end{array}$ & Carboplatin + radiotherapy \\
\hline Chloroquine & $\begin{array}{l}\text { Phase } 2 \text { clinical trial } \\
\text { (ongoing)-NCT02432417 }\end{array}$ & Chloroquine $+\mathrm{TMZ}+$ radiotherapy \\
\hline Adavosertib & $\begin{array}{l}\text { Phase } 1 \text { clinical trial } \\
\text { (ongoing)—NCT01849146 }\end{array}$ & Adavosertib $+\mathrm{TMZ}+$ radiotherapy \\
\hline AZD1390 & $\begin{array}{c}\text { Phase } 1 \text { clinical trial } \\
\text { (ongoing)-NCT03423628 }\end{array}$ & AZD1390 + radiotherapy \\
\hline
\end{tabular}

\section{Delivery Methods for Nanoparticles in Malignant Gliomas}

Delivery of therapeutics to the brain is an ongoing challenge in the treatment of brain tumors, particularly in GBM. Despite efforts to devise new treatment strategies, these lesions invariably recur as more aggressive and resistant to conventional treatment. Different approaches have been tested for NP administration in clinical and pre-clinical settings as nanotechnology rises as an alternative in the armamentarium to treat this devastating disease (Figure 3). Nanomedicine approaches can open therapeutic opportunities to improve effectiveness and outcomes through synergistic effort with established therapies.

\subsection{Systemic Administration}

Intravenous administration has been the most widely used route of administration for different types of NP tested preclinically. Kefayat et al. investigated folic acid (FA) and BSA decorated gold nanoclusters (FA-AuNCs) as a radiosensitizer in tumors derived from C6 cells (rat glioma). To evaluate FA-AuNCs intracranial distribution, the nanoclusters were injected intravenously in tumor-bearing rats one week after intracranial implantation 
of glioma cells. Biofunctionalization with FA helped to achieve a higher concentration of AuNCs in cancer tissue compared to healthy brain parenchyma. This also caused significant deposition of radiation beams energy at the tumor and consequent cancer cells damage and enhancement of RT efficacy [52]. Groups receiving radiation were delivered a single dose of $6 \mathrm{~Gy}$ using a compact linear accelerator. Subsequently, Kefayat et al. demonstrated that glioma-bearing rats' median survival times were significantly higher at RT + FA-AuNCs (24.5 days) compared with radiation alone (18 days) [52].

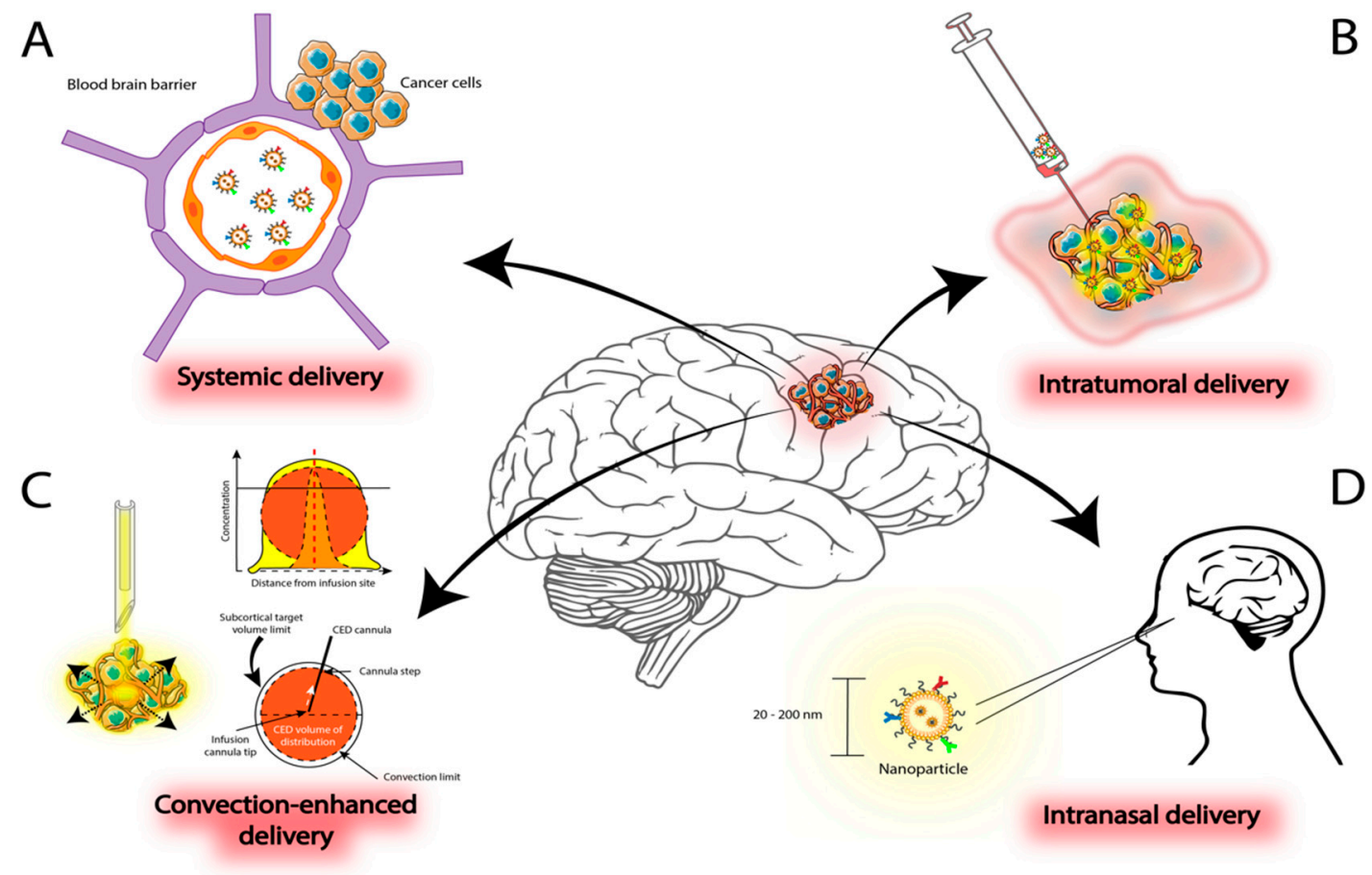

Figure 3. Different routes of Distribution of Nanoparticles in Glioblastoma. (A) Systemic delivery is a common route of distribution; however, it may be limited by the BBB. (B) Intratumoral delivery overcomes limitations imposed by BBB constraints but the NP may be localized to the site of injection. This limitation is improved by CED (C). (D) Intranasal delivery is a promising route for NP delivery, but it is still under study. Abbreviations: BBB-blood-brain barrier, NPnanoparticle, CED—Convection-enhanced delivery.

Since heavy elements in NP were proposed as an appropriate alternative to improve radiosensitization, Bhattarai et al. studied gold nanotriangles (AuNTs) as a possible radiation sensitizer in mice. To produce high quality monodisperse AuNTs, they used a convergent batchwise seed-mediated method. In vitro and in vivo tests were performed to determine effectiveness: uptake of AuNTs with different molecular weights ligands, cytotoxic dose in MCF-7, radiation experiments with radio-resistant U87MG human GBM cells and biodistribution and radiation effects in mice with U87MG implanted tumors. After tumor implanted growth, AuNTs were injected intravenous in bearing mice. As concluded, AuNTs have no cytotoxicity and exhibit good performance in radiosensitization [64].

Temozolomide (TMZ), a prodrug releasing a DNA alkylating agent, is considered as an effective drug in patients with GBM due to its penetrating BBB capacity. Despite being generally well tolerated, toxicities associated with TMZ include nausea, fatigue, and hematological side effects, including thrombocytopenia $[60,69,70]$. Zong et al. developed angiopep-2 (A2) modified lipid-poly NP for TMZ delivery to achieve synergistic effects against glioma. The NP were injected in tail vein to subsequently penetrate the BBB and enter the glioma tumor due to the EPR effect and active target [71]. In this study, mice with xenograft glioma were divided into seven groups $(n=10)$. Different lines of treatment were evaluated: PBS, PBS + RT, A2-PLGA + RT, free TMZ + RT, A2-P(MIs)25 + RT, A2$\mathrm{P}(\mathrm{MIs}) 25 / \mathrm{TMZ}+\mathrm{RT}$ and A2-PLGA/TMZ. With this design, the in vitro and in vivo results 
demonstrated that these A2- P(MIs)25/TMZ can efficiently target glioma to increase the concentration of TMZ (hypoxic cell radiosensitizers). Additionally, the therapeutic studies showed that A2-P(MIs)25/TMZ can effectively inhibit the growth of glioma cells and significantly improve mice survival time without adverse effects [71].

Additionally, intravenous administration requires attention in certain aspects, especially a detailed biodistribution analysis, to identify the mechanisms of particle elimination and discriminate between the particle concentration reached in the tumor and in the surrounding healthy tissue [45]. Likewise, other studies have been carried out via intravenous injection using high-Z metal NP for enhanced RT in preclinical models [72-76].

\subsection{Intratumoral Delivery}

The intratumoral approach, an alternative route of administering NP, is designed to overcome problems associated with drug delivery, including dispersion, penetration, and retention of the agent. Improving absorption and diffusion of the agent itself within the tumor microenvironment would result in better outcomes and improved efficacy of drug administration.

In this regard, Peidang et al. evaluated the efficacy of intratumoral administration of silver nanoparticles (AgNPs) in combination with a single dose of ionizing radiation at clinically relevant megavoltage energies for the treatment of C6 glioma-bearing rats [77]. $\mathrm{NP}$ were stereotactically administered on day 8 after tumor implantation. Rats bearing glioma received $10 \mathrm{~Gy}$ radiation one day following AgNPs injection. The antiproliferative and proapoptotic effects were obtained when gliomas were treated with AgNPs followed by RT. The therapeutic efficacy of AgNPs in combination with radiation in the absence of systemic toxicity is encouraging for further application in clinical settings. Later, Peidang et al. compared the radiosensitizing effects of AuNPs and AgNPs on gliomas at clinically relevant megavoltage energies [65]. Both high- $Z$ metal NP potentiated the in vitro and in vivo antiglioma effects of radiation, although there were higher rates of apoptotic cell death using AgNPs. Additionally, when radiation was added, AgNPs showed a significant increase in autophagy levels as compared with AuNPs. These findings support the potential application of AgNPs as an effective nanoradiosensitizer for the treatment of glioma with superior outcomes.

To increase specific and long-term retention of NP, Brachi et al. studied the system NP-Hydrogel [78]. The particles were embedded within a thermosensitive hydrogel, following intratumoral administration in GBM. Using a fluorophore (BODIPY) encapsulated inside infrared dye (cyanine 7)-labeled polyurethane (PUR) NP, retention and distribution dynamics were subsequently examined in orthotopic GBM-bearing mice over time. The results show that NP-Hydrogel had a significantly longer intratumoral retention compared to free NP and covered a significantly larger area of the tumor and the peritumor region. Additionally, these findings suggest that combining both delivery systems may increase the therapeutic window of intratumoral-administered drugs. This encourages combining delivery methods and approaches to enhance the therapeutic effects of drugs used in the treatment of brain tumors in clinical settings.

\section{Novel Strategies to Synergize with Nanoparticle-Based Radiosensitizers \\ 4.1. Stem Cells}

Mesenchymal stem cells (MSCs) possess certain qualities that make them suitable for this strategy, such as hypoimmunogenicity, fast ex vivo expansion, and inherent tumortropic and migratory properties [79]. These cells can track infiltrating cancer cells, which are responsible for promoting future recurrences, even beyond the location of the macroscopic tumor itself. Bioengineering techniques have been developed to modify these cells for inoculating various cell therapy alternatives, such as viral vectors, small interfering RNA (siRNA), prodrugs, and NP. Certainly, combinatorial approaches are currently of great interest given the considerable enhancement of therapeutic effects. Among them is the inhibition of glioma growth through controlling aspects involved in the cell cycle, and improving NP-related properties, such as improving diffusion toward the tumor nucleus 
and distal infiltrating tumor foci. This implies the internalization of the content in a stem cell before migrating and thus taking advantage of the cellular tropism, or simply the interaction of surfaces as conjugation for the same purpose. Therefore, it is considered a dual advancement. Our group has previously described the potential advantages of using combined approaches such as nanoparticle-based stem cell therapy in malignant glioma: (1) stem cells carry bigger cargos, increasing NP loading capacity; (2) big NP can be transported through the BBB; (3) stem cells improve delivery localizing therapeutic effect into the hypoxic central glioma core, overcoming treatment-resistant cancer stem cells (CSC); (4) tracking while delivering their cargo to CSC leaving the tumor bulk, which is considered to be one of the main reasons for tumor recurrence [23].

\subsection{Stereotactic Radiosurgery}

An additional potential approach to synergize with radiosensitizers is the use of SRS rather than standard fractionated RT in GBM patients. In general, RT of the brain involves two main modalities of radiation delivery: fractionated RT, and SRS. Radiosurgery has arisen as an important clinical tool in the management of brain tumors, as it can spare much more healthy brain tissue when compared to standard fractionated RT.

\subsubsection{Potential Benefit of Radiosurgery in Glioblastoma}

The current management of GBM includes maximal safe resection followed by adjuvant chemoradiation. This standard treatment implies the delivery of traditionally fractionated RT, where 60 Gy are delivered over six weeks to a volume including postsurgical cavity plus $2 \mathrm{~cm}$ margin. On the other hand, SRS delivers a large dose of highly conformal radiation to a specified target while limiting the dose to normal tissue in a single or hypofractionated intervention (up to five fractions). SRS has been studied in preclinical models of glioma. SRS induces cellular changes within the tumor, as well as modifying the tumor microenvironment. Briefly, the high dose delivered by SRS can ablate dividing cells, inducing senescence within non-ablated cells, stimulate local tumor immunity, and promote antitumor immune responses via a host of molecular mechanisms [80]. In addition, SRS causes the release of tumor-associated antigens, which initiates the cascade of an adaptive immune response, activating antigen-presenting cells and further priming of cytotoxic CD8 ${ }^{+} \mathrm{T}$ cells [81].

Taken together, radiation might counteract the immunosuppressive tumor microenvironment of GBM by increasing major histocompatibility complex (MHC) class I expression [82], enhancing the presentation of normally suppressed tumor-associated antigens while increasing the expression of proinflammatory cytokines, promoting dendritic cell maturation, and downregulating Fas ligand expression [83-85]. Immunogenic cell death (ICD) is characterized by the exposure of calreticulin on the surface of dying cells, the release of ATP, and the secretion of high-mobility group box 1 protein into the tumor microenvironment. These markers of ICD can expand antigen presentation and subsequent $\mathrm{CD}^{+} \mathrm{T}$ cell activation in GBM $[82,86]$. In this context, Zeng et al. investigated the combination of anti-PD-1 immunotherapy with stereotactic radiation in a mouse orthotopic GBM model, on the premise that immunotherapy can work synergistically with radiation, which has been shown to increase antigen presentation and promote a proinflammatory tumor microenvironment, as noted above. This group demonstrated that combining antiPD-1 therapy plus radiation improved survival compared with standard modality alone. Although neither PD-1 blockade nor single-session focal RT alone eradicated intracranial gliomas, the combination of these therapies generated robust, durable responses [83]. Despite efforts to increase the effectiveness of therapeutics in the tumor microenvironment, a major challenge for this approach is reaching tumor cells that are resistant to these modalities and do not respond to therapy. Therefore, it is of interest to study other therapies that can synergize and increase effectiveness, to overcome the heterogeneous and malignant behavior of tumor cells. Radiosensitization is one of these approaches and will be discussed in the following subsection. 
In the last decade, neoadjuvant SRS was proposed as a therapeutic approach [87-89]. Routman et al. described the role of preoperative SRS in brain metastases. When compared to postoperative SRS, preoperative SRS could offer comparable local control, decreased radiation necrosis rates and leptomeningeal disease, and would avoid the delay introduced by the required time for wound healing between surgery and postoperative radiation. The lack of pathologic confirmation before preoperative SRS is a concern, although less so given more reliable non-invasive diagnostic methods, such as liquid biopsies, that allow clinicians to more accurately determine malignancy without the need for biopsy [87]. Although SRS has been studied in GBM, the role of preoperative SRS in this pathology is still not clear [90].

\subsubsection{Nanoparticle Radiosensitization and Preoperative Radiation in GBM}

With recent discoveries, it has become apparent that improving the current approach to overcome the barriers in the treatment of GBM could potentially improve long-term outcomes in patients. The cytotoxicity of RT is caused by DNA double-strand breaks (DSBs) generated directly by the radiation or indirectly through the generation of reactive oxygen species, as noted above. Nevertheless, only $2 \%$ of the damage caused by this technique generates these cytotoxic DSBs directly [91]. Therefore, other strategies are required to increase tumor toxicity caused by RT to improve effectiveness and obtain better long-term results. SRS is safe and is routinely used to deliver RT to intracranial tumors. Although the infiltrative nature of GBM would preclude the use of SRS as a primary treatment modality, new data suggest that SRS should be reexamined when used in combination with different therapeutics such as NP [83]. This combination could enhance the response of tumor cells by inhibiting resistance properties, improve radiation dosimetry, or improve the delivery of chemotherapy. Additionally, timing plays an important role when radiation is employed. A neoadjuvant approach to RT might offer potential improvements in local control rates while decreasing toxicity. Thus, preoperative SRS could be used in conjunction with radiosensitizers. To date, high atomic element nanomaterials are often utilized as radiosensitizers due to their unique photoelectric decay characteristics. AuNPs are widely investigated and are considered as ideal radiosensitizers for RT because of their X-ray absorption and physical properties. Despite promising results, its clinical translation still faces many challenges. Among the few advances in the clinical use of preoperative RT and NP, NBTXR3 NP were investigated in a phase 1 trial (NCT01433068) that started in 2011 and was completed in 2015. The results show that human injection (22 sarcoma patients in France) was well tolerated until $10 \%$ of tumor volume was achieved. NP were delivered alongside preoperative external beam RT and this did not result in leakage of these NP into the adjoining healthy tissues [92]. Alternative strategies have been proposed to balance treatment outcomes and side effects; however, to our knowledge, clinical studies designed to investigate the more suitable time for applying RT plus NP have not yet been performed in GBM.

In this context, more research is needed with alternative approaches to overcome the therapeutic resistance found during glioma therapy; opting for joint efforts of technologies to enhance effects. Clinical studies using stem cells as therapeutic tools in glioma patients show encouraging results. As our group has previously described, MSCs derived from adipose tissue are affordable and malleable enough to characterize with joint nanotechnology $[23,39]$. In addition, this approach can be synergized with of other technologies, such as SRS, and ideally maximize the therapeutic value ratio for patients with GBM.

Radiation and surgical resection are the keystones in the treatment of GBM. However, it is mandatory to involve other technologies to achieve better control of the disease and become current therapies more effective. Precisely, current challenges limiting the study of radiosensitizers in clinical trials lie in three fundamental categories: drug interactions, delivery systems, and preclinical models. To continue working towards this approach, we present the current landscape, summarized in Table 2. 
Table 2. Current challenges and future directions of radiosensitization.

\begin{tabular}{cc}
\hline Problem & Main Challenges Ahead \\
\hline Drug interactions & $\begin{array}{c}\text { Experimental studies focused on improving radiosensitization of } \\
\text { therapeutical agents and replication of antineoplastic effect } \\
\text { within the microenvironment. }\end{array}$ \\
Delivery systems & $\begin{array}{c}\text { Delivering agents to the tumor site more precisely, leveraging } \\
\text { existing technologies to monitor response and effectiveness (e.g., } \\
\text { post-treatment markers, advanced imaging techniques).Focus } \\
\text { studies to assess the functioning of delivery systems and their } \\
\text { efficacy against biological barriers, such as bypassing systemic } \\
\text { metabolism and the blood-brain barrier. }\end{array}$ \\
Preclinical models & $\begin{array}{c}\text { Adapting preclinical models of simulated tumor } \\
\text { microenvironment for radiosensitizer assessment to produce } \\
\text { more accurate tumor response data. }\end{array}$ \\
\hline
\end{tabular}

With a multidisciplinary effort, radiosensitizers could become a standard of treatment in the GBM approach. It is promising based on the results obtained so far and may help address the therapeutic deficiencies of current GBM management.

\section{Conclusions}

The use of NP for radiosensitization in GBM is an appealing approach that deserves thoughtful consideration. NP offer several therapeutic advantages derived from the possibility of bioengineering them to fit tumor-specific therapeutic requirements. Despite substantial efforts, this approach has not yet impacted the care of GBM patients, although synergistic approaches may boost its clinical significance.

One of these approaches is in combination with radiation, which can be delivered in a traditional or novel approach. We expect that nanomedicine and preoperative SRS will find their way together in radiosensitization without excluding additional potential synergistic proposals, such as simultaneous modulation of the tumor microenvironment.

Author Contributions: H.R.-G. and C.R.-L. reviewed the literature and wrote the first draft of the manuscript. H.R.-G. and C.R.-L. created the figures. H.R.-G. and C.R.-L. contributed equally to this paper. T.D.M., D.S.S., J.D.P. and D.M.T. critically revised the manuscript. H.R.-G., C.R.-L. and D.M.T. worked on the study conception and design. All authors analyzed the data, drafted the manuscript, and read and agreed to the published version of the manuscript.

Funding: This publication was made possible through the support of the Eveleigh Family Career Development Award for Cancer Research at Mayo Clinic in Florida.

Institutional Review Board Statement: Not applicable.

Informed Consent Statement: Not applicable.

Conflicts of Interest: The authors declare no conflict of interest.

\section{References}

1. Ostrom, Q.T.; Patil, N.; Cioffi, G.; Waite, K.; Kruchko, C.; Barnholtz-Sloan, J.S. CBTRUS statistical report: Primary Brain and Other Central Nervous System Tumors Diagnosed in the United States in 2013-2017. Neuro-Oncology 2020, 22, iv1-iv96. [CrossRef] [PubMed]

2. Stupp, R.; Mason, W.P.; van den Bent, M.J.; Weller, M.; Fisher, B.; Taphoorn, M.J.; Belanger, K.; Brandes, A.A.; Marosi, C.; Bogdahn, U.; et al. Radiotherapy plus concomitant and adjuvant temozolomide for glioblastoma. N. Engl. J. Med. 2005, 352, 987-996. [CrossRef] [PubMed]

3. Walker, M.D.; Alexander, E., Jr.; Hunt, W.E.; MacCarty, C.S.; Mahaley, M.S., Jr.; Mealey, J., Jr; Norrell, H.A.; Owens, G.; Ransohoff, J.; Wilson, C.B.; et al. Evaluation of $\mathrm{BCNU}$ and/or radiotherapy in the treatment of anaplastic gliomas. A cooperative clinical trial. J. Neurosurg. 1978, 49, 333-343. [CrossRef]

4. Chen, L.; Chaichana, K.L.; Kleinberg, L.; Ye, X.; Quinones-Hinojosa, A.; Redmond, K. Glioblastoma recurrence patterns near neural stem cell regions. Radiother. Oncol. 2015, 116, 294-300. [CrossRef] [PubMed] 
5. Stupp, R.; Taillibert, S.; Kanner, A.; Read, W.; Steinberg, D.; Lhermitte, B.; Toms, S.; Idbaih, A.; Ahluwalia, M.S.; Fink, K.; et al. Effect of tumor-treating fields plus maintenance temozolomide vs maintenance temozolomide alone on survival in patients with glioblastoma: A randomized clinical trial. JAMA 2017, 318, 2306-2316. [CrossRef] [PubMed]

6. Stupp, R.; Taillibert, S.; Kanner, A.A.; Kesari, S.; Steinberg, D.M.; Toms, S.A.; Taylor, L.P.; Lieberman, F.; Silvani, A.; Fink, K.L.; et al. Maintenance therapy with tumor-treating fields plus temozolomide vs temozolomide alone for glioblastoma: A randomized clinical Trial. JAMA 2015, 314, 2535-2543. [CrossRef] [PubMed]

7. Cantrell, J.N.; Waddle, M.R.; Rotman, M.; Peterson, J.L.; Ruiz-Garcia, H.; Heckman, M.G.; Quinones-Hinojosa, A.; Rosenfeld, S.S.; Brown, P.D.; Trifiletti, D.M. Progress Toward Long-Term Survivors of Glioblastoma. Mayo Clin. Proc. 2019, 94, 1278-1286. [CrossRef]

8. Walker, M.D.; Green, S.B.; Byar, D.P.; Alexander, E., Jr.; Batzdorf, U.; Brooks, W.H.; Hunt, W.E.; MacCarty, C.S.; Mahaley, M.S., Jr.; Mealey, J., Jr.; et al. Randomized comparisons of radiotherapy and nitrosoureas for the treatment of malignant glioma after surgery. N. Engl. J. Med. 1980, 303, 1323-1329. [CrossRef]

9. Bhaskaran, M.; Devegowda, V.G.; Gupta, V.K.; Shivachar, A.; Bhosale, R.R.; Arunachalam, M.; Vaishnavi, T. Current perspectives on therapies, including drug delivery systems, for managing glioblastoma multiforme. ACS Chem. Neurosci. 2020, 11, $2962-2977$. [CrossRef]

10. Attia, M.F.; Anton, N.; Wallyn, J.; Omran, Z.; Vandamme, T.F. An overview of active and passive targeting strategies to improve the nanocarriers efficiency to tumour sites. J. Pharm. Pharmacol. 2019, 71, 1185-1198. [CrossRef]

11. The European Commission. Commission Recommendation of 18 October 2011 on the definition of nanomaterial 2011/696/EU. Off. J. Eur. Union 2011, 275, 38-40.

12. Thimsen, E.; Johnson, M.; Zhang, X.; Wagner, A.J.; Mkhoyan, K.A.; Kortshagen, U.R.; Aydil, E.S. High electron mobility in thin films formed via supersonic impact deposition of nanocrystals synthesized in nonthermal plasmas. Nat. Commun. 2014, 5, 5822 [CrossRef]

13. Lee, J.H.; Warner, C.M.; Jin, H.E.; Barnes, E.; Poda, A.R.; Perkins, E.J.; Lee, S.W. Production of tunable nanomaterials using hierarchically assembled bacteriophages. Nat. Protoc. 2017, 12, 1999-2013. [CrossRef]

14. Portney, N.G.; Ozkan, M. Nano-oncology: Drug delivery, imaging, and sensing. Anal. Bioanal. Chem. 2006, 384, 620-630. [CrossRef]

15. Yeini, E.; Ofek, P.; Albeck, N.; Rodriguez Ajamil, D.; Neufeld, L.; Eldar-Boock, A.; Kleiner, R.; Vaskovich, D.; Koshrovski-Michael, S.; Dangoor, S.I.; et al. Targeting glioblastoma: Advances in drug delivery and novel therapeutic approaches. Adv. Ther. 2021, 4, 2000124. [CrossRef]

16. Villaverde, G.; Baeza, A. Targeting strategies for improving the efficacy of nanomedicine in oncology. Beilstein J. Nanotechnol. 2019, 10, 168-181. [CrossRef]

17. Kunjachan, S.; Pola, R.; Gremse, F.; Theek, B.; Ehling, J.; Moeckel, D.; Hermanns-Sachweh, B.; Pechar, M.; Ulbrich, K.; Hennink, W.E.; et al. Passive versus active tumor targeting using RGD- and NGR-modified polymeric nanomedicines. Nano Lett. 2014, 14, 972-981. [CrossRef]

18. Matsumura, Y.; Maeda, H. A new concept for macromolecular therapeutics in cancer chemotherapy: Mechanism of tumoritropic accumulation of proteins and the antitumor agent smancs. Cancer Res. 1986, 46, 6387-6392.

19. Greish, K. Enhanced permeability and retention of macromolecular drugs in solid tumors: A royal gate for targeted anticancer nanomedicines. J. Drug Target. 2007, 15, 457-464. [CrossRef]

20. Bazak, R.; Houri, M.; Achy, S.E.; Hussein, W.; Refaat, T. Passive targeting of nanoparticles to cancer: A comprehensive review of the literature. Mol. Clin. Oncol. 2014, 2, 904-908. [CrossRef] [PubMed]

21. Maeda, H. Toward a full understanding of the EPR effect in primary and metastatic tumors as well as issues related to its heterogeneity. Adv. Drug Deliv. Rev. 2015, 91,3-6. [CrossRef]

22. Caro, C.; Pozo, D. Polysaccharide colloids as smart vehicles in cancer therapy. Curr. Pharm. Des. 2015, 21, 4822-4836. [CrossRef]

23. Ruiz-Garcia, H.; Alvarado-Estrada, K.; Krishnan, S.; Quinones-Hinojosa, A.; Trifiletti, D.M. Nanoparticles for stem cell therapy bioengineering in glioma. Front. Bioeng. Biotechnol. 2020, 8, 558375. [CrossRef] [PubMed]

24. Kim, J.; Mondal, S.K.; Tzeng, S.Y.; Rui, Y.; Al-kharboosh, R.; Kozielski, K.K.; Bhargav, A.G.; Garcia, C.A.; Quiñones-Hinojosa, A.; Green, J.J. Poly(ethylene glycol)-Poly(beta-amino ester)-Based Nanoparticles for Suicide Gene Therapy Enhance Brain Penetration and Extend Survival in a Preclinical Human Glioblastoma Orthotopic Xenograft Model. ACS Biomater. Sci. Eng. 2020, 6, $2943-2955$. [CrossRef] [PubMed]

25. Daou, T.J.; Li, L.; Reiss, P.; Josserand, V.; Texier, I. Effect of poly(ethylene glycol) length on the in vivo behavior of coated quantum dots. Langmuir 2009, 25, 3040-3044. [CrossRef]

26. Conde, J.; Dias, J.T.; Grazú, V.; Moros, M.; Baptista, P.V.; de la Fuente, J.M. Revisiting 30 years of biofunctionalization and surface chemistry of inorganic nanoparticles for nanomedicine. Front. Chem. 2014, 2, 48. [CrossRef]

27. Pernia Leal, M.; Caro, C.; García-Martín, M.L. Shedding light on zwitterionic magnetic nanoparticles: Limitations for in vivo applications. Nanoscale 2017, 9, 8176-8184. [CrossRef]

28. Bertrand, N.; Leroux, J.C. The journey of a drug-carrier in the body: An anatomo-physiological perspective. J. Control. Release 2012, 161, 152-163. [CrossRef] [PubMed]

29. Okuda, T.; Kawakami, S.; Akimoto, N.; Niidome, T.; Yamashita, F.; Hashida, M. PEGylated lysine dendrimers for tumor-selective targeting after intravenous injection in tumor-bearing mice. J. Control. Release 2006, 116, 330-336. [CrossRef] [PubMed] 
30. Hussain, Z.; Khan, S.; Imran, M.; Sohail, M.; Shah, S.W.A.; de Matas, M. PEGylation: A promising strategy to overcome challenges to cancer-targeted nanomedicines: A review of challenges to clinical transition and promising resolution. Drug Deliv. Transl. Res. 2019, 9, 721-734. [CrossRef]

31. van Tellingen, O.; Yetkin-Arik, B.; de Gooijer, M.C.; Wesseling, P.; Wurdinger, T.; de Vries, H.E. Overcoming the blood-brain tumor barrier for effective glioblastoma treatment. Drug Resist. Updates 2015, 19, 1-12. [CrossRef] [PubMed]

32. Harder, B.G.; Blomquist, M.R.; Wang, J.; Kim, A.J.; Woodworth, G.F.; Winkles, J.A.; Loftus, J.C.; Tran, N.L. Developments in blood-brain barrier penetrance and drug repurposing for improved treatment of glioblastoma. Front. Oncol. 2018, 8, 462. [CrossRef] [PubMed]

33. Belykh, E.; Shaffer, K.V.; Lin, C.; Byvaltsev, V.A.; Preul, M.C.; Chen, L. Blood-Brain Barrier, Blood-Brain Tumor Barrier, and Fluorescence-Guided Neurosurgical Oncology: Delivering Optical Labels to Brain Tumors. Front. Oncol. 2020, 10, 739. [CrossRef]

34. Allen, T.M. Ligand-targeted therapeutics in anticancer therapy. Nat. Rev. Cancer 2002, 2, 750-763. [CrossRef]

35. Carter, P. Improving the efficacy of antibody-based cancer therapies. Nat. Rev. Cancer 2001, 1, 118-129. [CrossRef]

36. Zhang, P.; Miska, J.; Lee-Chang, C.; Rashidi, A.; Panek, W.K.; An, S.; Zannikou, M.; Lopez-Rosas, A.; Han, Y.; Xiao, T.; et al. Therapeutic targeting of tumor-associated myeloid cells synergizes with radiation therapy for glioblastoma. Proc. Natl. Acad. Sci. USA 2019, 116, 23714-23723. [CrossRef]

37. Kim, D.H.; Rozhkova, E.A.; Ulasov, I.V.; Bader, S.D.; Rajh, T.; Lesniak, M.S.; Novosad, V. Biofunctionalized magnetic-vortex microdiscs for targeted cancer-cell destruction. Nat. Mater. 2010, 9, 165-171. [CrossRef] [PubMed]

38. Song, Z.; Liu, T.; Chen, T. Overcoming blood-brain barrier by HER2-targeted nanosystem to suppress glioblastoma cell migration, invasion and tumor growth. J. Mater. Chem. B 2018, 6, 568-579. [CrossRef]

39. Ruiz-Garcia, H.; Alvarado-Estrada, K.; Schiapparelli, P.; Quinones-Hinojosa, A.; Trifiletti, D.M. Engineering Three-Dimensional Tumor Models to Study Glioma Cancer Stem Cells and Tumor Microenvironment. Front. Cell. Neurosci. 2020, $14,558381$. [CrossRef]

40. Hua, L.; Wang, Z.; Zhao, L.; Mao, H.; Wang, G.; Zhang, K.; Liu, X.; Wu, D.; Zheng, Y.; Lu, J.; et al. Hypoxia-responsive lipidpoly-(hypoxic radiosensitized polyprodrug) nanoparticles for glioma chemo- and radiotherapy. Theranostics 2018, 8, 5088-5105. [CrossRef]

41. Hadziahmetovic, M.; Shirai, K.; Chakravarti, A. Recent advancements in multimodality treatment of gliomas. Future Oncol. 2011, 7, 1169-1183. [CrossRef] [PubMed]

42. Bernsen, H.J.; Rijken, P.F.; Peters, H.; Raleigh, J.A.; Jeuken, J.W.; Wesseling, P.; van der Kogel, A.J. Hypoxia in a human intracerebral glioma model. J. Neurosurg. 2000, 93, 449-454. [CrossRef]

43. Shah, J.L.; Li, G.; Shaffer, J.L.; Azoulay, M.I.; Gibbs, I.C.; Nagpal, S.; Soltys, S.G. Stereotactic Radiosurgery and Hypofractionated Radiotherapy for Glioblastoma. Neurosurgery 2018, 82, 24-34. [CrossRef]

44. Kazmi, F.; Vallis, K.A.; Vellayappan, B.A.; Bandla, A.; Yukun, D.; Carlisle, R. Megavoltage radiosensitization of gold nanoparticles on a glioblastoma cancer cell line using a clinical platform. Int. J. Mol. Sci. 2020, 21, 429. [CrossRef]

45. Sancey, L.; Lux, F.; Kotb, S.; Roux, S.; Dufort, S.; Bianchi, A.; Crémillieux, Y.; Fries, P.; Coll, J.L.; Rodriguez-Lafrasse, C.; et al. The use of theranostic gadolinium-based nanoprobes to improve radiotherapy efficacy. Br. J. Radiol. 2014, 87, 20140134. [CrossRef]

46. Caban-Toktas, S.; Sahin, A.; Lule, S.; Esendagli, G.; Vural, I.; Karlı Oguz, K.; Soylemezoglu, F.; Mut, M.; Dalkara, T.; Khan, M.; et al. Combination of Paclitaxel and R-flurbiprofen loaded PLGA nanoparticles suppresses glioblastoma growth on systemic administration. Int. J. Pharm. 2020, 578, 119076. [CrossRef]

47. Chung, K.; Ullah, I.; Kim, N.; Lim, J.; Shin, J.; Lee, S.C.; Jeon, S.; Kim, S.H.; Kumar, P.; Lee, S.K. Intranasal delivery of cancertargeting doxorubicin-loaded PLGA nanoparticles arrests glioblastoma growth. J. Drug Target. 2020, 28, 617-626. [CrossRef] [PubMed]

48. Bhargav, A.G.; Mondal, S.K.; Garcia, C.A.; Green, J.J.; Quiñones-Hinojosa, A. Nanomedicine Revisited: Next Generation Therapies for Brain Cancer. Adv. Ther. 2020, 3, 2000118. [CrossRef]

49. Lux, F.; Tran, V.L.; Thomas, E.; Dufort, S.; Rossetti, F.; Martini, M.; Truillet, C.; Doussineau, T.; Bort, G.; Denat, F.; et al. AGuIX $\left({ }^{\circledR}\right)$ from bench to bedside-Transfer of an ultrasmall theranostic gadolinium-based nanoparticle to clinical medicine. Br. J. Radiol. 2019, 92, 20180365. [CrossRef] [PubMed]

50. Kuncic, Z.; Lacombe, S. Nanoparticle radio-enhancement: Principles, progress and application to cancer treatment. Phys. Med. Biol. 2018, 63, 02TR0102. [CrossRef]

51. Lacombe, S.; Porcel, E.; Scifoni, E. Particle therapy and nanomedicine: State of art and research perspectives. Cancer Nanotechnol. 2017, 8, 9. [CrossRef]

52. Kefayat, A.; Ghahremani, F.; Motaghi, H.; Amouheidari, A. Ultra-small but ultra-effective: Folic acid-targeted gold nanoclusters for enhancement of intracranial glioma tumors' radiation therapy efficacy. Nanomedicine 2019, 16, 173-184. [CrossRef]

53. Hainfeld, J.F.; Dilmanian, F.A.; Zhong, Z.; Slatkin, D.N.; Kalef-Ezra, J.A.; Smilowitz, H.M. Gold nanoparticles enhance the radiation therapy of a murine squamous cell carcinoma. Phys. Med. Biol. 2010, 55, 3045-3059. [CrossRef]

54. Kunoh, T.; Shimura, T.; Kasai, T.; Matsumoto, S.; Mahmud, H.; Khayrani, A.C.; Seno, M.; Kunoh, H.; Takada, J. Use of DNAgenerated gold nanoparticles to radiosensitize and eradicate radioresistant glioma stem cells. Nanotechnology 2019, $30,055101$. [CrossRef] 
55. Séhédic, D.; Chourpa, I.; Tétaud, C.; Griveau, A.; Loussouarn, C.; Avril, S.; Legendre, C.; Lepareur, N.; Wion, D.; Hindré, F.; et al. Locoregional confinement and major clinical benefit of ${ }^{188}$ re-loaded CXCR4-Targeted nanocarriers in an orthotopic human to mouse model of glioblastoma. Theranostics 2017, 7, 4517-4536. [CrossRef]

56. Barbero, S.; Bonavia, R.; Bajetto, A.; Porcile, C.; Pirani, P.; Ravetti, J.L.; Zona, G.L.; Spaziante, R.; Florio, T.; Schettini, G. Stromal cell-derived factor $1 \alpha$ stimulates human glioblastoma cell growth through the activation of both extracellular signal-regulated kinases 1/2 and Akt. Cancer Res. 2003, 63, 1969.

57. Le Duc, G.; Roux, S.; Paruta-Tuarez, A.; Dufort, S.; Brauer, E.; Marais, A.; Truillet, C.; Sancey, L.; Perriat, P.; Lux, F.; et al. Advantages of gadolinium based ultrasmall nanoparticles vs molecular gadolinium chelates for radiotherapy guided by MRI for glioma treatment. Cancer Nanotechnol. 2014, 5, 4. [CrossRef]

58. Alric, C.; Taleb, J.; Le Duc, G.; Mandon, C.; Billotey, C.; Le Meur-Herland, A.; Brochard, T.; Vocanson, F.; Janier, M.; Perriat, P.; et al Gadolinium chelate coated gold nanoparticles as contrast agents for both X-ray computed tomography and magnetic resonance imaging. J. Am. Chem. Soc. 2008, 130, 5908-5915. [CrossRef]

59. Jarrett, B.R.; Gustafsson, B.; Kukis, D.L.; Louie, A.Y. Synthesis of ${ }^{64} \mathrm{Cu}$-labeled magnetic nanoparticles for multimodal imaging. Bioconjug. Chem. 2008, 19, 1496-1504. [CrossRef]

60. Badiyan, S.N.; Markovina, S.; Simpson, J.R.; Robinson, C.G.; DeWees, T.; Tran, D.D.; Linette, G.; Jalalizadeh, R.; Dacey, R.; Rich, K.M.; et al. Radiation therapy dose escalation for glioblastoma multiforme in the era of temozolomide. Int. J. Radiat. Oncol. Biol. Phys. 2014, 90, 877-885. [CrossRef]

61. Verry, C.; Sancey, L.; Dufort, S.; Le Duc, G.; Mendoza, C.; Lux, F.; Grand, S.; Arnaud, J.; Quesada, J.L.; Villa, J.; et al. Treatment of multiple brain metastases using gadolinium nanoparticles and radiotherapy: NANO-RAD, a phase I study protocol. BMJ Open 2019, 9, e023591. [CrossRef]

62. Verry, C.; Dufort, S.; Villa, J.; Gavard, M.; Iriart, C.; Grand, S.; Charles, J.; Chovelon, B.; Cracowski, J.-L.; Quesada, J.-L.; et al. Theranostic AGuIX nanoparticles as radiosensitizer: A phase I, dose-escalation study in patients with multiple brain metastases (NANO-RAD trial). Radiother. Oncol. 2021, 160, 159-165. [CrossRef]

63. Nwagwu, C.D.; Immidisetti, A.V.; Bukanowska, G.; Vogelbaum, M.A.; Carbonell, A.M. Convection-Enhanced delivery of a firstin-class anti- $\beta 1$ integrin Antibody for the treatment of high-grade glioma utilizing real-time imaging. Pharmaceutics 2020, 13, 40. [CrossRef]

64. Bhattarai, S.R.; Derry, P.J.; Aziz, K.; Singh, P.K.; Khoo, A.M.; Chadha, A.S.; Liopo, A.; Zubarev, E.R.; Krishnan, S. Gold nanotriangles: Scale up and X-ray radiosensitization effects in mice. Nanoscale 2017, 9, 5085-5093. [CrossRef]

65. Liu, P.; Jin, H.; Guo, Z.; Ma, J.; Zhao, J.; Li, D.; Wu, H.; Gu, N. Silver nanoparticles outperform gold nanoparticles in radiosensitizing U251 cells in vitro and in an intracranial mouse model of glioma. Int. J. Nanomed. 2016, 11, 5003-5014. [CrossRef]

66. Liu, Z.; Tan, H.; Zhang, X.; Chen, F.; Zhou, Z.; Hu, X.; Chang, S.; Liu, P.; Zhang, H. Enhancement of radiotherapy efficacy by silver nanoparticles in hypoxic glioma cells. Artif. Cells Nanomed. Biotechnol. 2018, 46, S922-S930. [CrossRef]

67. Shirvalilou, S.; Khoei, S.; Khoee, S.; Mahdavi, S.R.; Raoufi, N.J.; Motevalian, M.; Karimi, M.Y. Enhancement radiation-induced apoptosis in $\mathrm{C} 6$ glioma tumor-bearing rats via $\mathrm{pH}$-responsive magnetic graphene oxide nanocarrier. J. Photochem. Photobiol. B Biol. 2020, 205, 111827. [CrossRef]

68. Verry, C.; Dufort, S.; Lemasson, B.; Grand, S.; Pietras, J.; Troprès, I.; Crémillieux, Y.; Lux, F.; Mériaux, S.; Larrat, B.; et al. Targeting brain metastases with ultrasmall theranostic nanoparticles, a first-in-human trial from an MRI perspective. Sci. Adv. 2020, 6 , eaay5279. [CrossRef]

69. Friedman, H.S.; Kerby, T.; Calvert, H. Temozolomide and treatment of malignant glioma. Clin. Cancer Res. 2000, 6, $2585-2597$.

70. Chang, S.M.; Theodosopoulos, P.; Lamborn, K.; Malec, M.; Rabbitt, J.; Page, M.; Prados, M.D. Temozolomide in the treatment of recurrent malignant glioma. Cancer 2004, 100, 605-611. [CrossRef]

71. Zong, Z.; Hua, L.; Wang, Z.; Xu, H.; Ye, C.; Pan, B.; Zhao, Z.; Zhang, L.; Lu, J.; Mei, L.H.; et al. Self-Assembled angiopep-2 modified lipid-poly (hypoxic radiosensitized polyprodrug) nanoparticles delivery TMZ for glioma synergistic TMZ and RT therapy. Drug Deliv. 2019, 26, 34-44. [CrossRef]

72. Joh, D.Y.; Sun, L.; Stangl, M.; Al Zaki, A.; Murty, S.; Santoiemma, P.P.; Davis, J.J.; Baumann, B.C.; Alonso-Basanta, M.; Bhang, D.; et al. Selective targeting of brain tumors with gold nanoparticle-induced radiosensitization. PLoS ONE 2013, 8, e62425. [CrossRef]

73. Chen, N.; Yang, W.; Bao, Y.; Xu, H.; Qin, S.; Tu, Y. BSA capped Au nanoparticle as an efficient sensitizer for glioblastoma tumor radiation therapy. RSC Adv. 2015, 5, 40514-40520. [CrossRef]

74. Shevtsov, M.A.; Nikolaev, B.P.; Ryzhov, V.A.; Yakovleva, L.Y.; Marchenko, Y.Y.; Parr, M.A.; Rolich, V.I.; Mikhrina, A.L.; Dobrodumov, A.V.; Pitkin, E.; et al. Ionizing radiation improves glioma-specific targeting of superparamagnetic iron oxide nanoparticles conjugated with cmHsp70.1 monoclonal antibodies (SPION-cmHsp70.1). Nanoscale 2015, 7, 20652-20664. [CrossRef] [PubMed]

75. Xing, H.; Zheng, X.; Ren, Q.; Bu, W.; Ge, W.; Xiao, Q.; Zhang, S.; Wei, C.; Qu, H.; Wang, Z.; et al. Computed tomography imagingguided radiotherapy by targeting upconversion nanocubes with significant imaging and radiosensitization enhancements. Sci. Rep. 2013, 3, 1751. [CrossRef]

76. Sun, L.; Joh, D.Y.; Al-Zaki, A.; Stangl, M.; Murty, S.; Davis, J.J.; Baumann, B.C.; Alonso-Basanta, M.; Kaol, G.D.; Tsourkas, A.; et al. Theranostic Application of mixed gold and superparamagnetic iron oxide nanoparticle micelles in glioblastoma multiforme. $J$. Biomed. Nanotechnol. 2016, 12, 347-356. [CrossRef] [PubMed]

77. Liu, P.; Huang, Z.; Chen, Z.; Xu, R.; Wu, H.; Zang, F.; Wang, C.; Gu, N. Silver nanoparticles: A novel radiation sensitizer for glioma? Nanoscale 2013, 5, 11829-11836. [CrossRef] [PubMed] 
78. Brachi, G.; Ruiz-Ramírez, J.; Dogra, P.; Wang, Z.; Cristini, V.; Ciardelli, G.; Rostomily, R.C.; Ferrari, M.; Mikheev, A.M.; Blanco, E.; et al. Intratumoral injection of hydrogel-embedded nanoparticles enhances retention in glioblastoma. Nanoscale 2020, 12, 23838-23850. [CrossRef] [PubMed]

79. Wang, X.; Gao, J.; Ouyang, X.; Wang, J.; Sun, X.; Lv, Y. Mesenchymal stem cells loaded with paclitaxel-poly(lactic-co-glycolic acid) nanoparticles for glioma-targeting therapy. Int. J. Nanomed. 2018, 13, 5231-5248. [CrossRef] [PubMed]

80. Zhang, L.; Cheng, F.; Wei, Y.; Zhang, L.; Guo, D.; Wang, B.; Li, W. Inhibition of TAZ contributes radiation-induced senescence and growth arrest in glioma cells. Oncogene 2019, 38, 2788-2799. [CrossRef]

81. Lee, Y.; Auh, S.L.; Wang, Y.; Burnette, B.; Meng, Y.; Beckett, M.; Sharma, R.; Chin, R.; Tu, T.; Weichselbaum, R.R.; et al. Therapeutic effects of ablative radiation on local tumor require $\mathrm{CD}^{+} \mathrm{T}$ cells: Changing strategies for cancer treatment. Blood 2009, 114, 589-595. [CrossRef]

82. Lehrer, E.J.; McGee, H.M.; Peterson, J.L.; Vallow, L.; Ruiz-Garcia, H.; Zaorsky, N.G.; Sharma, S.; Trifiletti, D.M. Stereotactic radiosurgery and immune checkpoint inhibitors in the management of brain metastases. Int. J. Mol. Sci. 2018, 19, 3054. [CrossRef] [PubMed]

83. Zeng, J.; See, A.P.; Phallen, J.; Jackson, C.M.; Belcaid, Z.; Ruzevick, J.; Durham, N.; Meyer, C.; Harris, T.J.; Albesiano, E.; et al. Anti-PD-1 blockade and stereotactic radiation produce long-term survival in mice with intracranial gliomas. Int. J. Radiat. Oncol. Biol. Phys. 2013, 86, 343-349. [CrossRef]

84. Klein, B.; Loven, D.; Lurie, H.; Rakowsky, E.; Nyska, A.; Levin, I.; Klein, T. The effect of irradiation on expression of HLA class I antigens in human brain tumors in culture. J. Neurosurg. 1994, 80, 1074-1077. [CrossRef]

85. Newcomb, E.W.; Demaria, S.; Lukyanov, Y.; Shao, Y.; Schnee, T.; Kawashima, N.; Lan, L.; Dewyngaert, J.K.; Zagzag, D.; McBride, W.H.; et al. The combination of ionizing radiation and peripheral vaccination produces long-term survival of mice bearing established invasive GL261 gliomas. Clin. Cancer Res. 2006, 12, 4730. [CrossRef]

86. Golden, E.B.; Pellicciotta, I.; Demaria, S.; Barcellos-Hoff, M.H.; Formenti, S.C. The convergence of radiation and immunogenic cell death signaling pathways. Front. Oncol. 2012, 2, 88. [CrossRef]

87. Routman, D.M.; Yan, E.; Vora, S.; Peterson, J.; Mahajan, A.; Chaichana, K.L.; Laack, N.; Brown, P.D.; Parney, I.F.; Burns, T.C.; et al. Preoperative stereotactic radiosurgery for brain metastases. Front. Neurol. 2018, 9, 959. [CrossRef]

88. Sauer, R.; Becker, H.; Hohenberger, W.; Rödel, C.; Wittekind, C.; Fietkau, R.; Martus, P.; Tschmelitsch, J.; Hager, E.; Hess, C.F.; et al. Preoperative versus postoperative chemoradiotherapy for rectal cancer. N. Engl. J. Med. 2004, 351, 1731-1740. [CrossRef]

89. Tienhoven, G.V.; Versteijne, E.; Suker, M.; Groothuis, K.B.C.; Busch, O.R.; Bonsing, B.A.; Hingh, I.H.J.T.d.; Festen, S.; Patijn, G.A.; Vos-Geelen, J.d.; et al. Preoperative chemoradiotherapy versus immediate surgery for resectable and borderline resectable pancreatic cancer (PREOPANC-1): A randomized, controlled, multicenter phase III trial. J. Clin. Oncol. 2018, 36, LBA4002. [CrossRef]

90. Deora, H.; Tripathi, M.; Tewari, M.K.; Ahuja, C.K.; Kumar, N.; Kaur, A.; Kamboj, P. Role of gamma knife radiosurgery in the management of intracranial gliomas. Neurol. India 2020, 68, 290-298. [CrossRef]

91. Kievit, F.M.; Wang, K.; Ozawa, T.; Tarudji, A.W.; Silber, J.R.; Holland, E.C.; Ellenbogen, R.G.; Zhang, M. Nanoparticle-Mediated knockdown of DNA repair sensitizes cells to radiotherapy and extends survival in a genetic mouse model of glioblastoma. Nanomedicine 2017, 13, 2131-2139. [CrossRef]

92. Bonvalot, S.; Le Pechoux, C.; De Baere, T.; Kantor, G.; Buy, X.; Stoeckle, E.; Terrier, P.; Sargos, P.; Coindre, J.M.; Lassau, N.; et al. First-in-Human Study testing a new radioenhancer using nanoparticles (NBTXR3) Activated by radiation therapy in patients with locally advanced soft tissue sarcomas. Clin. Cancer Res. 2017, 23, 908. [CrossRef] 